\title{
A qualitative analysis of an almost-periodic Beddington-DeAngelis predator-prey system with mutual interference and time delay
}

Demou Luo ${ }^{1}$

${ }^{1}$ Sun Yat-Sen University

May 5, 2020

\begin{abstract}
Of concern is the existence and uniqueness of a predator-prey model with Beddington-DeAngelis functional response and mutual interference. By constructing a suitable Lyapunov function and using the comparison theorem of ordinary differential equation, we prove that the existence, permanence and uniqueness of a positive globally attractive almost periodic solution of the model. A more general and frequent example will be offered to describe our main theorem.
\end{abstract}

\section{Hosted file}

elsarticle-template-num.pdf available at https://authorea.com/users/300209/articles/429869a-qualitative-analysis-of-an-almost-periodic-beddington-deangelis-predator-prey-systemwith-mutual-interference-and-time-delay

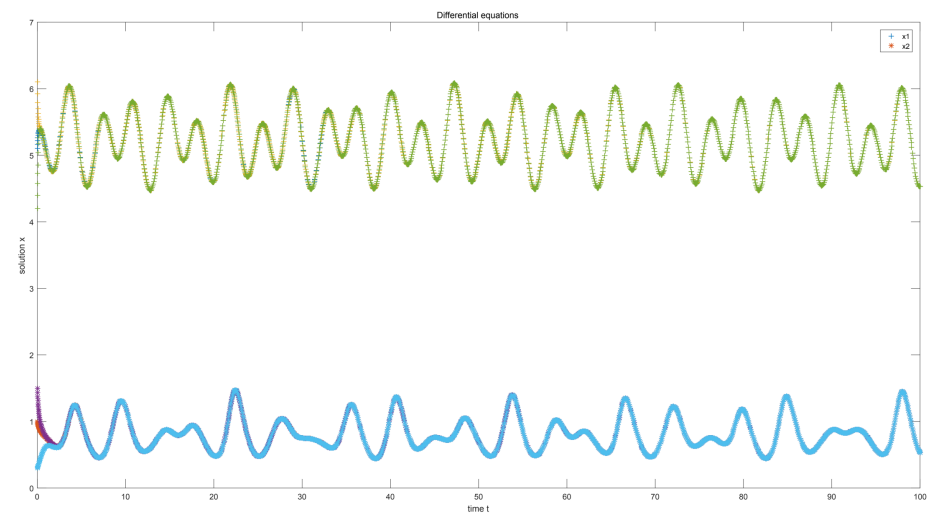




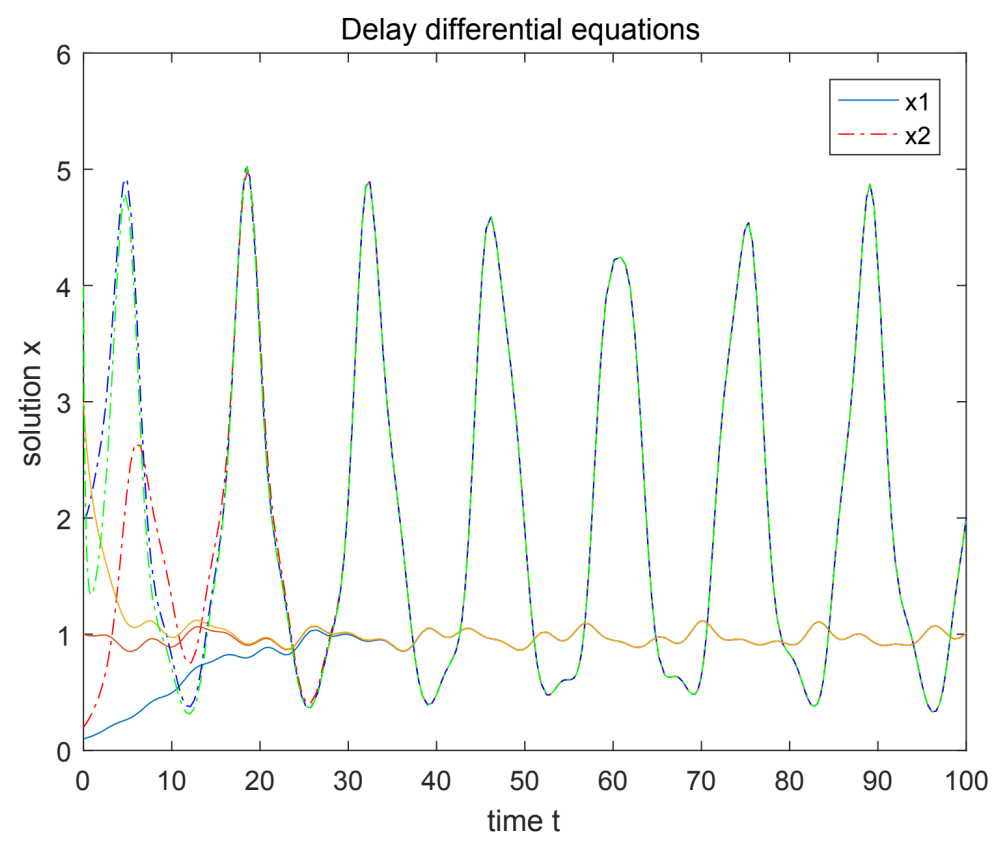

